\title{
Micropapillary Bladder Cancer Metastatic to the Breast: A Case Report and Brief Literature Review
}

\author{
ELENA LIEVORE ${ }^{1}$, LETTERIO RUNZA $^{2}$, MICHELE GHIDINI $^{1}$, BARBARA GALASSI $^{3}$, ANDREA GALLIOLI ${ }^{1}$, \\ CAROLINA BEBI ${ }^{1}$, LUCA BOERI $^{1}$, CONCETTA BLUNDO ${ }^{4}$, CLAUDIA FRANCESCA ROSSI ${ }^{4}$, \\ FABRIZIO LONGO ${ }^{1}$, GIANCARLO ALBO ${ }^{1,5}$, EMANUELE MONTANARI ${ }^{1,5}$ and ELISA DE LORENZIS ${ }^{1,5}$ \\ ${ }^{1}$ Department of Urology, Foundation IRCCS Ca' Granda Ospedale Maggiore Policlinico, Milan, Italy; \\ ${ }^{2}$ Department of Anatomical Pathology, Foundation IRCCS Ca' Granda Ospedale Maggiore Policlinico, Milan, Italy; \\ ${ }^{3}$ Department of Oncology, Foundation IRCCS Ca' Granda Ospedale Maggiore Policlinico, Milan, Italy; \\ ${ }^{4}$ Department of Breast Surgery, Foundation IRCCS Ca' Granda Ospedale Maggiore Policlinico, Milan, Italy; \\ ${ }^{5}$ Department of Clinical Sciences and Community Health, University of Milan, Milan, Italy
}

\begin{abstract}
Background: Bladder cancer (BC) usually metastasizes to the lymph nodes, bone, lung, liver and peritoneum, but rarely in the breast. Case Report: We present a case of a 66-year-old female diagnosed with a massive bladder tumor, who presented a right mammary nodule after neo-adjuvant chemotherapy. A biopsy of the nodule did not permit a definite diagnosis of metastatic spread, which was confirmed by excision of the nodule. In the literature, we found only 7 other similar cases of $B C$ metastasis to the breast. Currently, a non-invasive method for differentiating a breast metastasis from primary cancer is lacking, although there are some clinical and radiological aspects that may help the diagnosis. Histological examination provides diagnostic certainty. Conclusion: Breast metastases from BC are unusual and consequently difficult to identify without non-invasive tools. Clinical history and histological study play a pivotal role in determining the correct diagnosis.
\end{abstract}

Bladder cancer (BC) is the $7^{\text {th }}$ most commonly diagnosed cancer in males, and $11^{\text {th }}$ when both genders are considered (1). $\mathrm{BC}$ incidence and mortality rates vary across countries due to differences in risk factors, detection and diagnostic practices.

This article is freely accessible online.

Correspondence to: Elisa De Lorenzis (ORCID iD https://orcid.org/0000-0002-5961-9874), MD, FEBU, Department of Clinical Sciences and Community Health, University of Milan, Department of Urology, Foundation IRCCS Ca' Granda Ospedale Maggiore Policlinico, Via della Commenda 15, 20122 Milan, Italy. Tel: +39 0255034546, Fax: +39 0250320584, e-mail: elisa.delorenzis@gmail.com

Key Words: Metastasis, urothelial cancer, breast cancer, neoadjuvant therapy, immunotherapy.
Radical cystectomy is the standard treatment for localized muscle-invasive BC (2). Cisplatin-based neo-adjuvant chemotherapy (NAC) has been used since the 1980s (3) but only recent studies have demonstrated a real survival benefit from $\mathrm{NAC}$, which has become consequently one of the mainstay of the multimodal treatments for muscle-invasive $\mathrm{BC}(4,5)$. Ten to fifteen percent of patients affected by $\mathrm{BC}$ are already metastatic at diagnosis (6). Before the development of effective chemotherapy, patients with metastatic urothelial cancer had a median survival rarely exceeding three to six months. Surgical resection of the primary or metastases is part of a multimodal approach in various malignancies yielding potentially better survival and/or quality of life, although the role of surgery in metastatic BC has not yet been determined (7). The most common locations for metastases from $\mathrm{BC}$ are lymph nodes, bone, lung, liver and peritoneum. Several uncommon locations have been reported, such as brain, skin and pericardial effusion (8). Breast metastases are extremely rare (9). Usually, the most common source of a metastatic breast lesion is the contralateral breast, which should therefore be thoroughly studied as a first step when a mammary mass is identified. It is consequently obvious that a correct and early identification of a metastatic disease is essential to direct the patient to an appropriate treatment. Here, we present a case of breast metastasis from micropapillary variant $\mathrm{BC}$ and we provide a brief review of the literature regarding this occurrence.

\section{Case Presentation}

A 66-years old female patient was referred to a urological consultant for recurrent urinary tract infections and severe pain in the hypogastric region. She underwent an abdominal computed tomography (CT) scan showing a massive bladder tumor occupying the left bladder trigone and third degree left hydronephrosis. A thoracic CT scan showed bilateral lung 
micronodules, which were too small to be characterized. A transurethral resection of the bladder tumor was performed, with concomitant positioning of a left nephrostomic drainage, identifying a muscle-invasive high-grade urothelial carcinoma, with features of glandular differentiation. A multidisciplinary consultation group indicated therapy with NAC, cisplatin and gemcitabine (10) followed by radical cystectomy. NAC doses were reduced to $90 \%$ of the full doses according to renal dysfunction. The restaging CT scan, however, showed a reduction of the bladder mass, stable pulmonary nodules and appearance of both left iliac adenopathy and a right mammary nodule of $8 \mathrm{~mm}$ (Figure 1A). A Positron Emission Tomography (PET)-CT scan revealed increased uptake in the left iliac lymph nodes but no uptake in the breast. The breast surgeon applied ultrasound (US) and confirmed the presence of a non-palpable well-circumscribed round hypoechoic nodule of $7,8 \mathrm{~mm}$, which was not associated with axillary lymphadenopathies (Figure 1B). A biopsy of the nodule diagnosed a scarcely differentiated, invasive carcinoma, with micropapillary characteristics, that was suggestive for both breast primary tumor and bladder secondary lesion. Clinically, the patient required every-day therapy with NSAIDs and transdermal fentanyl for pain management. The case was, therefore, referred to our center and a re-evaluation of the biopsy slides was performed, which confirmed the presence of muscle-invasive high-grade urothelial carcinoma with glandular and micropapillary features in the bladder. The breast specimens were defined as suggestive of a metastasis from $\mathrm{BC}$, in relation to the patient's oncological history. After discussion in a multidisciplinary setting, palliative radical cystectomy with ureteroileal-cutaneous urinary diversion was proposed to the patient in order to relieve bladder pain and to resolve the hydronephrosis. Considering the rarity of the histological variant of the $\mathrm{BC}$ and the unusual location of the metastasis, concomitant excision of the mammary nodule was indicated for pathological confirmation. An US and X-Rayguided carbon marking of the breast mass was performed preoperatively (Figure 1C). The definitive histological examination of the bladder specimen showed a full thickness high-grade urothelial carcinoma of micropapillary variant and focal $(<10 \%)$ glandular differentiation, extensively ulcerated, with positive surgical margins and pathological lymph nodes (8 over a total of 21) (ypT3bypN2ypM1b). Only the excisional biopsy of the mammary nodule confirmed the diagnosis of metastasis from micropapillary carcinoma of the bladder. The $\mathrm{H} \& \mathrm{E}$ stain (Figure 2A) showed morula-like aggregates of cuboidal to columnar neoplastic cells, devoid of fibrovascular core, with micropapillary differentiation, as seen also in the bladder specimen (Figure 2B). Immunohistochemical staining of the nodule showed positive results for E-cadherin (basolateral), epithelial membrane antigen (EMA), uroplakin, GATA3 (Figure 2C), cytokeratin (CK) 20 (Figure 3A), CK7 , Ki67 (60\%) and negative results for human epidermal growth factor receptor 2 (HER2/neu) (score 1), estrogen and progesterone receptors, and for mammaglobin (Figure 3B) and GCDFP-15 (Figure 3C). The bladder specimen was found to be negative for estrogen and progesterone receptors, positive for Ki67 (50\%) and borderline for HER2/neu (score 2+ basolateral pattern) but non amplified with dual-color chromogenic in situ hybridization (CISH). The 2 months follow-up CT scan showed multiple pulmonary nodules and para-aortic and left iliac lymphadenopathy. The patient was subsequently treated with immunotherapy with checkpoint inhibitors (pembrolizumab). Up to now, 3 cycles have been administered without side effects. The patient is currently alive (10 months from diagnosis, 6 months from surgery).

Declaration of patient consent. We have obtained an appropriate patient consent form. In the form, the patient has given her consent for her images and other clinical information to be reported in the journal. The patient understands that her names and initials will not be published, and due efforts will be made to conceal her identity, but anonymity cannot be guaranteed.

\section{Discussion}

We performed a PubMed search in order to collect any previous reports in English language of metastasis of primary $\mathrm{BC}$ to the breast. To the best of our knowledge, we identified 7 cases (11-16) (summarized along with our case in Table I). Unfortunately, the majority of these cases were extrapolated from large series regarding solid and non-solid tumors metastatic to the breast. Therefore, clinical and histological data are not reported in detail, limiting the possibility of a direct comparison with our case. Moreover, half of the cases have been described before the year 2000, when the diagnostic and therapeutic approaches to muscle-invasive $\mathrm{BC}$ were different. For example, PET-CT was not widespread, and NAC was underused. Breast metastases are rare findings in $\mathrm{BC}$, and the breast per se is an uncommon site of secondary malignancies accounting for approximately $0.3-2.7 \%$ of all malignant mammary tumors (9). This very low rate of occurrence may be due to the breast tissue constitution, prevalently fibrotic with a relatively poor blood supply (17) and no clear risk factor for breast metastases has been identified so far (12). Currently there is no reliable noninvasive diagnostic tool for this type of metastasis, and given its rarity coupled with the high prevalence of primary mammary malignancies, a newly detected breast mass requires a thorough diagnostic workup even in the presence of a history of extramammary cancer. Consequently, histological examination is often necessary for certain diagnosis. Nonetheless, some clinical and radiological features may help in the differential diagnosis (18). Clinically, metastatic palpable masses are usually freely movable and well defined, 

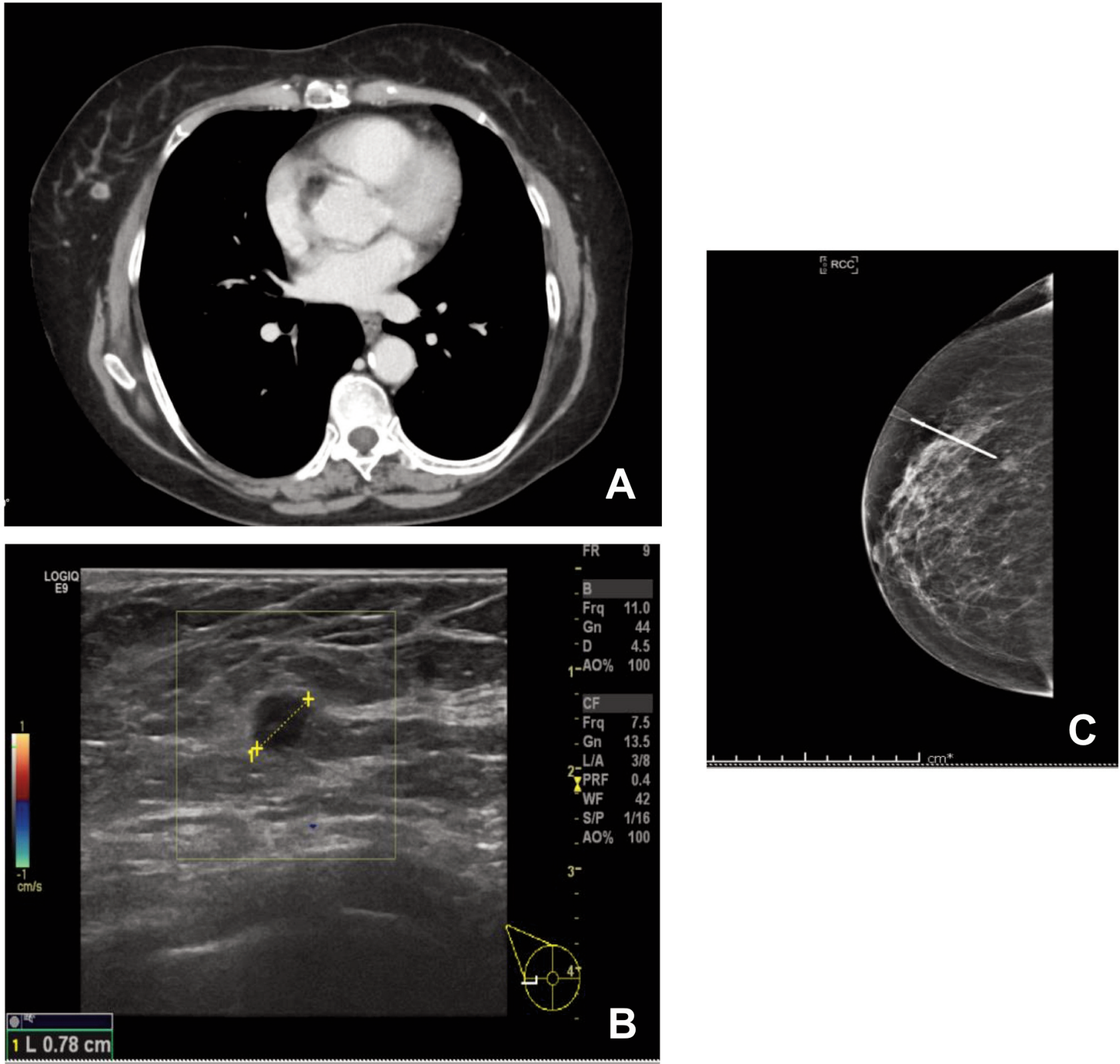

Figure 1. Radiological workup of metastasis to the breast (A) Contrast enhanced CT scan showing appearance of a right mammary nodule (arrow) (B) US appearance: a round hypoechoic mass in the lower outer quadrant of the right breast (C) Mammographic delimitation of the breast lesion before excision (cranio-caudal projection).

firm and round, without skin changes, and due to absence of desmoplastic reaction the dimensions perceived during clinical examination usually correlate to the radiological measurements (19). Breast metastases from extramammary malignancies are commonly located in the upper outer quadrant, grow rapidly and are located superficially or adjacent to the breast parenchyma. US usually shows hypoechoic masses that are round to oval, well-circumscribed or occasionally microlobulated, without architectural distortion nor secondary skin or nipple changes. When considering mammograms, the absence of calcification seems to be a typical feature of metastatic lesions to the breast $(9,20)$. In our case, the mammary mass was non palpable and located in the right lower outer quadrant, presented no skin changes and no calcification at mammogram. The hypothesis of a BC metastasis was made in relation to the history of high-grade $\mathrm{BC}$ with lymph-node progression after NAC. In order to achieve a certain diagnosis a core biopsy was indicated. 

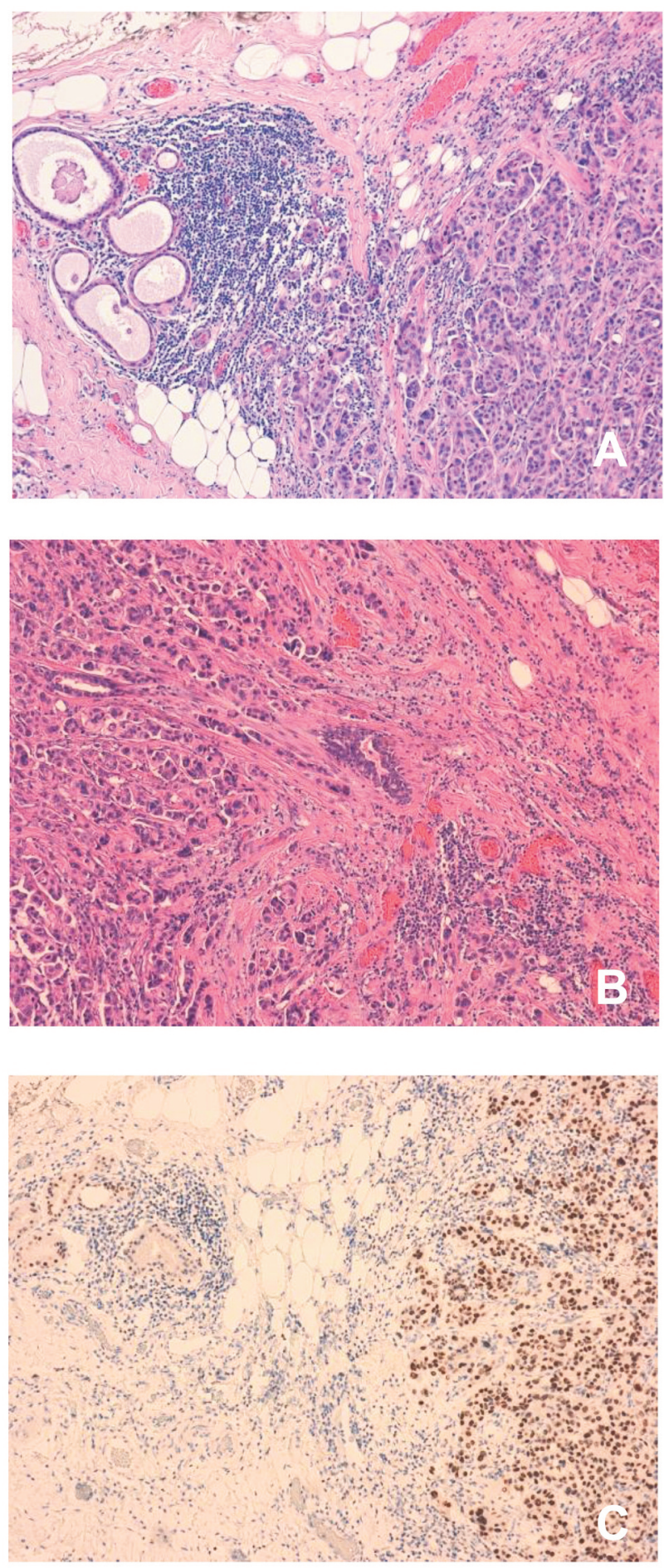

Figure 2. Histological examination of breast and bladder surgical excision specimen: (A) Healthy breast parenchyma on the left and metastatic micropapillary bladder cancer on the right $(H \& E, \times 10),(B)$ micropapillary urothelial carcinoma with lymphovascular invasion of neoplastic cells ( $H \& E$ stain, $\times 20),(C)$ positive nuclear staining for GATA3 (immunohistochemistry, $\times 10$ ).
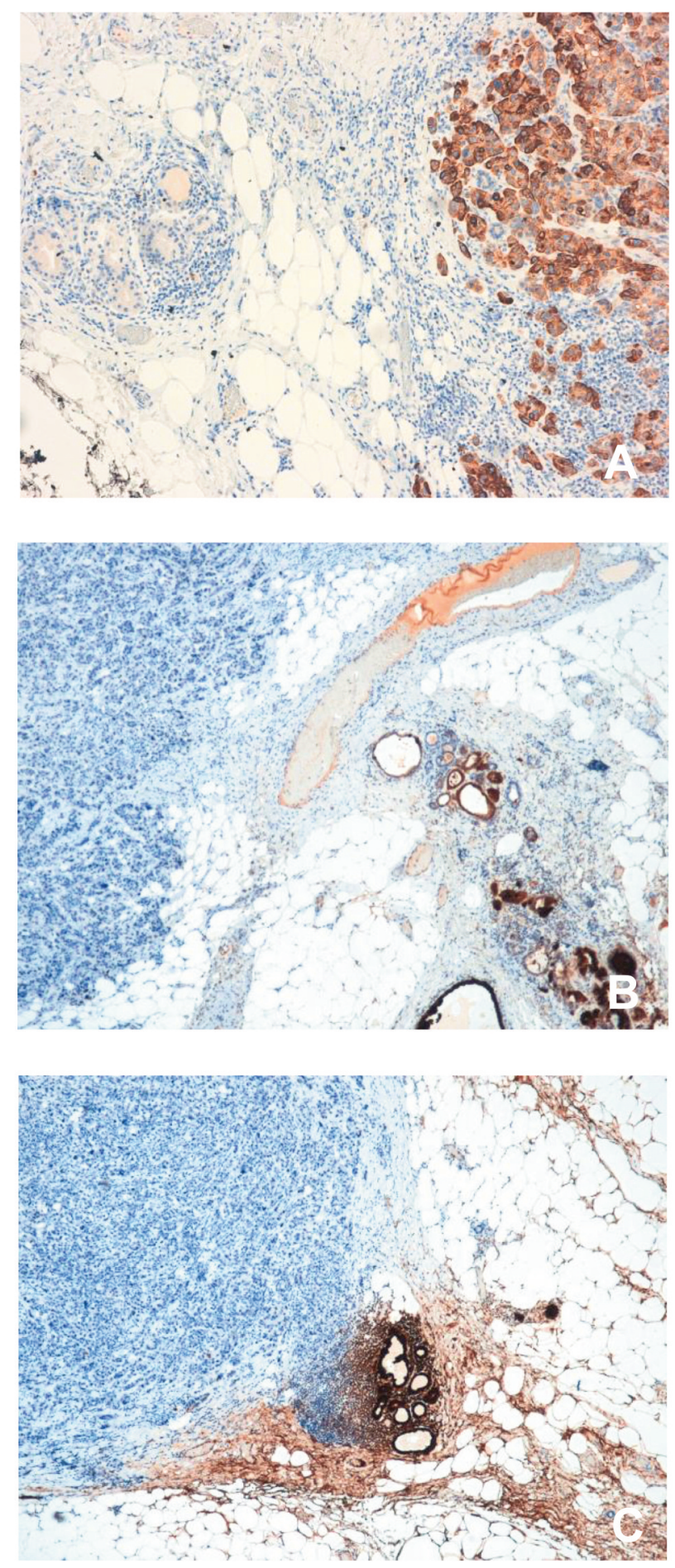

Figure 3. Immunohistochemistry analysis in mammary nodule excision: $(A)$ CK20 positivity in mammary metastatic cells (immunohistochemistry, $\times 10$ ), (B) negative mammoglobin in metastatic cells (immunohistochemistry, $\times 5$ ), (C) negativity for GCDFP15 in metastatic cells (immunohistochemistry, $\times 5$ ). 
Table I. Summary of cases of breast metastases from bladder cancer found in literature.

\begin{tabular}{|c|c|c|c|c|c|c|}
\hline $\begin{array}{l}\text { Author, } \\
\text { year }\end{array}$ & $\begin{array}{l}\text { Age, } \\
\text { gender }\end{array}$ & $\begin{array}{l}\text { Mtx } \mathrm{R} / \mathrm{L} \\
\text { and size }\end{array}$ & $\begin{array}{l}\text { Mtx in other } \\
\text { organs }\end{array}$ & $\begin{array}{l}\text { Diagnostic } \\
\text { method }\end{array}$ & $\begin{array}{c}\text { Time from } \\
\text { diagnosis to } \mathrm{mtx}\end{array}$ & $\begin{array}{c}\text { Survival from } \\
\text { diagnosis of breast mtx }\end{array}$ \\
\hline $\begin{array}{l}\text { Haidu S, } \\
1972(11)\end{array}$ & N/A & $\mathrm{R}$ & N/A & Biopsy & N/A & N/A \\
\hline $\begin{array}{l}\text { Silverman JF, } \\
1987(12)\end{array}$ & $50, \mathrm{~F}$ & N/A & N/A & Fine-needle aspiration & N/A & N/A \\
\hline $\begin{array}{l}\text { Sneige N, } \\
1989(13)\end{array}$ & $55, \mathrm{M}$ & N/A & N/A & $\begin{array}{l}\text { Fine-needle aspiration + } \\
\text { simple mastectomy }\end{array}$ & 4 years & NED at 8 months FU \\
\hline $\begin{array}{l}\text { Belton AL, } \\
1997 \text { (14) }\end{array}$ & $57, \mathrm{~F}$ & $\mathrm{R}, 10 \mathrm{~mm}$ & Skin & Excision & 2 years & 8 months \\
\hline $\begin{array}{l}\text { Wood B, } \\
2008(15)\end{array}$ & $90, \mathrm{~F}$ & $\mathrm{~L}, 2 \times 20 \mathrm{~mm}$ & Absent & Fine-needle biopsy & 16 months & N/A \\
\hline $\begin{array}{l}\text { DeLair DF, } \\
2013 \text { (16) } \\
(2 \text { cases) }\end{array}$ & N/A & N/A & N/A & Biopsy/excision & N/A & N/A \\
\hline Present study & $66, \mathrm{~F}$ & $\mathrm{R}, 8 \mathrm{~mm}$ & $\begin{array}{l}\text { Iliac lymph } \\
\text { nodes }\end{array}$ & $\begin{array}{l}\text { Biopsy + nodule } \\
\text { excision }\end{array}$ & 3 months & $\begin{array}{c}\text { Alive with } \\
\text { progressive disease }\end{array}$ \\
\hline
\end{tabular}

N/A: Not available; F: female; M: male; Mtx: metastasis; R: right; L: left; NED: no evidence of disease.

The histological study is the fundamental diagnostic technique for correct identification of a breast metastasis. As seen from the other reports in Table I, breast fine needle biopsy is the preferred method, although Hajdu and Urban (11) have stated that, in case of dubious diagnosis, an entire excisional biopsy should be performed. Both Silverman et al. (12) and Sneige et al. (13) have instead provided the diagnosis with fine-needle aspiration cytology. The latter, however, included the $\mathrm{BC}$ case among those in which the cytology was compatible also with primary breast carcinoma, but the patient's cancer history was determinant of the definitive diagnosis. All studies agree that the oncological history is pivotal when a breast mass is newly discovered and, in presence of high-grade extra-mammary tumors, the nodule always needs to be addressed as a suspected metastasis. Moreover, DeLair et al. have reported that the major cause of histological diagnostic failure was related to the absence of a prior cancer history. The challenge in our case was mainly related to the fact that the biopsy specimens of both breast and bladder were analyzed in a different hospital. The initial diagnosis did not mention the micropapillary bladder histological variant, which can provide important prognostic data and validate the hypothesis of early distant spread, even after NAC. The diagnosis of this histological variation in fact shows only modest inter-operative reproducibility among pathologists (21). In the bladder specimen micropapillary carcinoma was clearly evidenced by hollow or morula-like aggregates of cuboidal to columnar neoplastic cells, devoid of fibrovascular core. Typical patterns of micropapillary differentiation were present, such as spongy stroma with clear and empty spaces around cell clusters and a delicate stromal framework composed of fibroblast and connective tissue. The clear spaces usually mimic lymphatic vessels, but they lack endothelial lining (22). The epithelial clusters typically show reverse polarity (23), with moderate versus severe cytologic atypia (high grade) and extensive lymphovascular invasion, supporting the aggressiveness of this histological variant. Breast and bladder tumors may show morphological overlap, also in immunocytochemical markers (24). In rare cases, only excisional biopsy can provide certainty, as evidenced by the series of 32 mammary metastases reported by Wood et al. In this series the transitional cell carcinoma metastasis diagnosis was performed through comparison between the original tumor and excisional specimens (15), rather than with fine needle biopsy. In our case breast excision was positive for the GATA3 marker, which is normally present both in breast and bladder primary tumors (25), and positive for uroplakin, which confirmed the micropapillary bladder carcinoma as the origin of the mass. Positivity for cytokeratin 20 also favored the urothelial origin hypothesis. Furthermore, the breast specimen was found to be negative for mammaglobin and GCDFP-15, which differs from the majority of primary breast tumors. Negativity for estrogen and progesterone receptors is instead widely described and associated with a poor prognosis (26). When a diagnosis of breast metastasis from $\mathrm{BC}$ is performed, the treatment of choice is cisplatin-based chemotherapy (3). The role of surgery in metastatic urothelial carcinoma is not yet established and most of the experience comes from retrospective studies (7). Second-line chemotherapy was the 
planned treatment for our patient; however, cystectomy was proposed to her given the poor quality of life achieved with the nephrostomy tube and with inadequate pain control, in addition to the surgical feasibility (relatively young age, low comorbidity index). Clinically, micropapillary tumor is almost invariably muscle invasive at the time of presentation with frequent lymph node involvement and widespread metastases to distant organs $(27,28)$. Generally, the clinical course of this histological variant is mostly poor with the 5-year and 10-year overall survival rates in the largest study being 74 and 54\%, respectively (22). In addition, overall prognosis for patients with metastatic cancer from different sites to the breast is poor $(29,30)$, as demonstrated also by our literature review: Sneige (13) has reported $80 \%$ death within one year, and DeLair presented a median survival of 15 months after breast metastasis diagnosis (16). This explains the rapid progression of the disease seen in our patient. Unfortunately, data regarding the reported cases do not permit a prediction of the biological behavior and the potential prognostic factors of $\mathrm{BC}$ metastasis to the breast.

\section{Conclusion}

$\mathrm{BC}$ metastasis to the breast is a rare but crucial diagnosis. Although some radiological characteristics may be helpful in distinguishing primary and secondary breast cancer, immunohistochemical staining of biopsy or surgical specimens are the most important tools to establish the diagnosis, even if fine-needle aspiration cytology can provide satisfactory results. The presence of $\mathrm{BC}$ metastasis to the breast may be indicative of a large spread of the primary tumor, or of an aggressive histology. Early recognition of this disease and a multidisciplinary approach can potentially optimize the treatment plan and goal of care in these patients.

\section{Conflicts of Interest}

The Authors declare that there are no conflicts of interest regarding this study.

\section{Authors' Contributions}

Elena Lievore: Study conception and design, acquisition of data, drafting of manuscript. Letterio Runza: study conception and design, drafting of manuscript. Michele Ghidini, Fabrizio Longo, Giancarlo Albo: critical revision. Barbara Galassi, Andrea Gallioli, Carolina Bebi: acquisition of data. Luca Boeri analysis and interpretation of data. Concetta Blundo: analysis and interpretation of data, drafting of manuscript. Claudia Francesca Rossi analysis and interpretation of data. Emanuele Montanari: study conception, critical revision. Elisa De Lorenzis: study conception and design, acquisition of data, critical revision.

\section{References}

1 Ferlay J, Steliarova-Foucher E, Lortet-Tieulent J, Rosso S, Coebergh JWW, Comber H, Forman D and Bray F: Cancer incidence and mortality patterns in Europe: Estimates for 40 countries in 2012. Eur J Cancer 49(6): 1374-1403, 2013. PMID: 23485231. DOI: 10.1016/j.ejca.2012.12.027

2 Stein JP, Lieskovsky G, Cote R, Groshen S, Feng AC, Boyd S, Skinner E, Bochner B, Thangathurai D, Mikhail M, Raghavan D and Skinner DG: Radical cystectomy in the treatment of invasive bladder cancer: long-term results in 1,054 patients. $\mathrm{J}$ Clin Oncol 19(3): 666-675, 2001. PMID: 11157016. DOI: 10.1200/JCO.2001.19.3.666

3 Witjes JA, Bruins M, Cathomas R, Compérat E, Cowan NC, Gakis G, Hernández V, Lorch A, Ribal MJ (Vice-chair), Thalmann GN, van der Heijden AG and Veskimäe E: EAU Guidelines on Muscle-Invasive and Metastatic Bladder Cancer, 2019.

4 Vale CL and Advanced Bladder Cancer (ABC) Meta-analysis Collaboration: Neoadjuvant chemotherapy in invasive bladder cancer: update of a systematic review and meta-analysis of individual patient data advanced bladder cancer (ABC) metaanalysis collaboration. Eur Urol 49(2): 202-205, 2005. PMID: 15939524. DOI: $10.1016 /$ j.eururo.2005.04.006

5 International Collaboration of Trialists, Medical Research Council Advanced Bladder Cancer Working Party, European Organisation for Research and Treatment of Cancer GenitoUrinary Tract Cancer Group, Australian Bladder Cancer Study Group, National Cancer Institute of Canada Clinical Trials Group, Finnbladder, Norwegian Bladder Cancer Study Group, Club Urologico Espanol de Tratamiento Oncologico Group, Griffiths G, Hall R, Sylvester R, Raghavan D and Parmar MKB: International Phase III trial assessing neoadjuvant cisplatin, methotrexate, and vinblastine chemotherapy for muscle-invasive bladder cancer: Long-term results of the BA06 30894 Trial. J Clin Oncol 29(16): 2171-2177, 2011. PMID: 21502557. DOI: 10.1200/JCO.2010.32.3139

6 Rosenberg JE, Carroll PR and Small EJ: Update con chemotherapy for advanced bladder cancer. J Urol 174(1): 14-20, 2005. PMID: 15947569. DOI: 10.1097/01.ju.0000162039.38023.5f

7 Abufaraj M, Dalbagni G, Daneshmand S, Horenblas S, Kamat AM, Kanzaki R, Zlotta AR and Shariat SF: The role of surgery in metastatic bladder cancer: A systematic review. Eur Urol 73(4): 543557, 2018. PMID: 29122377. DOI: 10.1016/j.eururo.2017.09.030

8 Shinagare AB, Ramaiya NH, Jagannathan JP, Fennessy FM, Taplin M-E and Van den Abbeele AD: Metastatic pattern of bladder cancer: correlation with the characteristics of the primary tumor. Am J Roentgenol 196(1): 117-122, 2011. PMID: 21178055. DOI: 10.2214/AJR.10.5036

9 Lee SK, Kim WW, Kim SH, Hur SM, Kim S, Choi JH, Cho EY, Han SY, Hahn BK, Choe JH, Kim JH, Kim JS, Lee JE, Nam SJ and Yang JH: Characteristics of metastasis in the breast from extramammary malignancies. J Surg Oncol 101(2): 137-140, 2010. PMID: 20082359. DOI: 10.1002/jso.21453

10 von der Maase H: Gemcitabine and cisplatin in locally advanced and/or metastatic bladder cancer. Eur J Cancer 36: 13-16, 2000. PMID: 10908843. DOI: 10.1016/s09598049(00)00080-0

11 Hajdu S and Urban J: Cancers metastatic to the breast. Cancer 29(6): 1691-1696,1972. PMID: 4337956. DOI: 10.1002/10970142(197206)29:6<1691::aid-cncr2820290637>3.0.co;2-4 
12 Silverman JF, Feldman P, Covell JL and Frable WJ: Fine needle aspiration cytology of neoplasms metastatic to the breast. Acta Cytol 31(3): 291-300, 1987. PMID: 3473862.

13 Sneige N, Zachariah S, Fanning TV, Dekmezian RH and Ordóñez NG: Fine-needle aspiration cytology of metastatic neoplasms in the breast. Am J Clin Pathol 92(1): 27-35, 1989. PMID: 2750705. DOI: 10.1093/ajcp/92.1.27

14 Belton AL, Stull MA, Grant T and Shepard MH: Mammographic and sonographic findings in metastatic transitional cell carcinoma of the breast. Am J Roentgenol 168(2): 511-512, 1997. PMID: 9016237. DOI: 10.2214/ajr.168.2.9016237

15 Wood B, Sterrett G, Frost F and Swarbrick N: Diagnosis of extramammary malignancy metastatic to the breast by fine needle biopsy. Pathology 40(4): 345-351, 2008. PMID: 18446623. DOI: 10.1080/00313020801911520.

16 Delair DF, Corben AD, Catalano JP, Vallejo CE, Brogi E and Tan LK: Non-mammary metastases to the breast and axilla: A study of 85 cases. Mod Pathol 26(3): 343-349, 2013. PMID: 23174933. DOI: 10.1038/modpathol.2012.191.

17 Kwan WH, Choi PH, Li CK, Shing MK, Chik KW, Yuen P and Chow LT: Breast metastasis in adolescents with alveolar rhabdomyosarcoma of the extremities: report of two cases. Pediatr Hematol Oncol 13(3): 277-285, 1996. PMID: 8735345. DOI: $10.3109 / 08880019609030828$

18 Mun SH, Ko EY, Han B-K, Shin JH, Kim SJ and Cho EY: Breast metastases from extramammary malignancies: typical and atypical ultrasound features. Korean J Radiol 15(1): 20-28, 2014. PMID: 24497788. DOI: 10.3348/kjr.2014.15.1.20

19 Bohman LG, Bassett LW, Gold RH and Voet R: Breast metastases from extramammary malignancies. Radiology 144(2): 309312,1987. PMID: 7089284. DOI: 10.1148/radiology.144.2.7089284

20 Alexander HR, Turnbull AD and Rosen PP: Isolated breast metastases from gastrointestinal carcinomas: Report of two cases. J Surg Oncol 42(4): 264-266, 1989. PMID: 2556613. DOI: $10.1002 /$ jso.2930420412

21 Sangoi AR, Beck AH, Amin MB, Cheng L, Epstein JI, Hansel DE, Iczkowski KA, Lopez-Beltran A, Oliva E, Paner GP, Reuter VE, Ro JY, Shah RB, Shen SS, Tamboli P and McKenney JK: Interobserver reproducibility in the diagnosis of invasive micropapillary carcinoma of the urinary tract among urologic pathologists. Am J Surg Pathol 34(9): 1367-1376, 2010. PMID: 20717002. DOI: 10.1097/PAS.0b013e3181ec86b3

22 Kamat AM, Dinney CPN, Gee JR, Grossman HB, SiefkerRadtke AO, Tamboli P, Detry MA, Robinson TL and Pisters LL: Micropapillary bladder cancer. Cancer 110(1): 62-67, 2007. PMID: 17542024. DOI: $10.1002 /$ cncr.22756
23 Nassar H: Carcinomas with micropapillary morphology: Clinical significance and current concepts. Adv Anat Pathol 11(6): 297-303, 2004. PMID: 15505530. DOI: 10.1097/01.pap.0000138142.26882.fe

$24 \mathrm{Xu} \mathrm{W,} \mathrm{Xia} \mathrm{H,} \mathrm{Liu} \mathrm{W,} \mathrm{Zheng} \mathrm{W} \mathrm{and} \mathrm{Hua} \mathrm{L:} \mathrm{Exploration} \mathrm{of}$ genetics commonness between bladder cancer and breast cancer based on a silcio analysis on disease subtypes. Technol Health Care 26(Suppl 1): 361-377, 2018. PMID: 29758961. DOI: 10.3233/THC-174699

25 Liu H, Shi J, Wilkerson ML and Lin F: Immunohistochemical evaluation of GATA3 expression in tumors and normal tissues: A useful immunomarker for breast and urothelial carcinomas. Am J Clin Pathol 138(1): 57-64, 2012. PMID: 22706858. DOI: 10.1309/AJCP5UAFMSA9ZQBZ

26 Luna-Moré S, Casquero S, Pérez-Mellado A, Rius F, Weill B and Gornemann I: Importance of estrogen receptors for the behavior of invasive micropapillary carcinoma of the breast. Review of 68 cases with follow-up of 54. Pathol - Res Pract 196(1): 35-39, 2000. PMID: 10674270. DOI: 10.1016/S0344-0338(00)80019-9

27 Kwon GY and Ro JY: Micropapillary variant of urothelial carcinoma. Adv Urol 2011: 217153, 2011. PMID: 22007200. DOI: $10.1155 / 2011 / 217153$

28 Guo CC, Dadhania V, Zhang L, Majewski T, Bondaruk J, Sykulski M, Wronowska V, Gambin A, Wang Y, Zhang S, Fuentes-Mattei E, Kamat AM, Dinney C, Siefker-Radtke A, Choi W, Baggerly KA, McConkey D, Weinstein JN and Czerniak B: Gene expression profile of the clinically aggressive micropapillary variant of bladder cancer. Eur Urol 70(4): 611-620, 2016. PMID: 26988609. DOI: 10.1016/j.eururo.2016.02.056

29 Toombs B and Kalisher L: Metastatic disease to the breast: clinical, pathologic, and radiographic features. Am J Roentgenol 129(4): 673-676, 1977. PMID: 409241. DOI: 10.2214/ajr.129.4.673

$30 \mathrm{McCrea}$ ES, Johnston C and Haney PJ: Metastases to the breast. Am J Roentgenol 141(4): 685-690, 1983. PMID: 6604418. DOI: 10.2214/ajr.141.4.685
Received September 24, 2020

Revised October 14, 2020

Accepted October 15, 2020 